\title{
Penerapan WEMA dalam Peramalan Data IHSG
}

\author{
Seng Hansun \\ Program Studi Teknik Informatika, Universitas Multimedia Nusantara, Tangerang, Indonesia \\ hansun@umn.ac.id
}

Diterima 9 Desember 2013

Disetujui 23 Desember 2013

\begin{abstract}
Abstrak-One of the most popular technical indicator used in time series analysis for predicting future data is the Moving Average method. During its' development, many variation and implementation have been made by researchers, one of them is the Weighted Exponential Moving Average (WEMA) which is introduced by Hansun.
\end{abstract}

In this paper, we will try to implement the WEMA method on one of stock market change indicator in Indonesia, i.e. the Jakarta Stock Exchange (JKSE) composite index data. The research is continued by calculating the accuracy and robustness of WEMA method, using MSE and MAPE criteria. The result shows that the WEMA method can be used to predict JKSE data and it's quite accurate.

Kata kunci-time series analysis, JKSE, moving average, WEMA

\section{PENDAHULUAN}

Data runtun waktu (time series) adalah suatu rangkaian pengamatan berdasarkan urutan waktu dari karakteristik kuantitatif dari satu atau kumpulan kejadian yang diambil dalam periode waktu tertentu [1]. Untuk memahami karakteristik-karakteristik yang dimiliki oleh suatu data runtun waktu, para peneliti telah mengadopsi metode-metode analisis data runtun waktu (time series analysis) dengan tujuan agar dapat menemukan suatu keteraturan atau pola yang dapat digunakan dalam peramalan kejadian mendatang [2, $3,4]$.

Salah satu metode analisis data runtun waktu yang banyak digunakan adalah metode moving average. Moving average masih dipertimbangkan sebagai metode terbaik oleh banyak orang mengingat kemudahan, objektivitas, kehandalan, dan faedahnya [5].

Metode moving average memiliki berbagai bentuk, namun tujuan utamanya tetap sama, yakni untuk melacak pola tren dalam suatu data runtun waktu yang diberikan $[5,6]$. Jenis yang paling sederhana adalah Simple Moving Average (SMA). Dalam SMA, setiap data dalam data runtun waktu diberi bobot yang sama, tanpa melihat dimana data tersebut muncul dalam barisan data runtun waktu. Weighted Moving Average (WMA) merupakan pengembangan dari SMA yang memberikan suatu faktor bobot untuk tiap data dalam data runtun waktu, sementara Exponential Moving Average (EMA) merupakan variasi lain dari WMA yang menggunakan bilangan eksponensial sebagai dasar dalam pembentukan faktor bobot dalam analisis data runtun waktu.

Hansun [7] dalam penelitiannya telah memperkenalkan sebuah pendekatan baru dalam metode moving average untuk analisis data runtun waktu. Dalam penelitiannya, cara perhitungan faktor bobot metode WMA dan EMA dimodifikasi dan dikombinasikan untuk memperoleh faktor bobot yang baru yang dapat digunakan dalam peramalan data runtun waktu. Pendekatan ini dikenal sebagai metode Weighted Exponential Moving Average (WEMA). Untuk itu, dalam tulisan ini, peneliti akan mencoba untuk menerapkan metode WEMA dalam peramalan data IHSG (Indeks Harga Saham Gabungan). Dengan peramalan data IHSG ini, para pelaku pasar dapat memprediksi kenaikan atau penurunan harga saham di masa mendatang melalui analisis teknikal data runtun waktu. Untuk menghitung tingkat akurasi dan kehandalan peramalan data runtun waktu, digunakan kriteria MSE (Mean Square Error) dan MAPE (Mean Absolute Percentage Error).

\section{METODE WEIGHTED EXPONENTIAL MOVING AVERAGE}

Dalam peramalan data runtun waktu IHSG, peneliti menerapkan metode WEMA (Weighted Exponential Moving Average) sebagai teknik peramalan dan kriteria MSE (Mean Square Error) serta MAPE (Mean Absolute Percentage Error) untuk mengukur tingkat akurasi dan kehandalan hasil peramalan yang dilakukan.

\section{A. WEMA (Weighted Exponential Moving Average)}

WEMA merupakan suatu pendekatan baru dalam analisis teknikal data runtun waktu yang menggabungkan cara perhitungan faktor bobot pada metode WMA (Weighted Moving Average) 
dan EMA (Exponential Moving Average). Dalam pendekatan ini, pertama akan digunakan formula perhitungan bobot WMA, yakni 'sum of digits' [8], untuk memperoleh suatu nilai prediksi baru untuk suatu data tertentu dalam data runtun waktu. Namun demikian, nilai prediksi tersebut tidak akan langsung digunakan sebagai nilai hasil peramalan, melainkan akan digunakan sebagai nilai dasar untuk selanjutnya dihitung dengan menggunakan faktor bobot EMA.

Berikut prosedur algoritma yang dilakukan dalam pendekatan WEMA yang diusulkan oleh Hansun [7],

1. Hitung nilai dasar, $H_{t}$, untuk data runtun waktu dan periode yang diberikan, dengan menggunakan persamaan berikut,

$$
H_{t}=\frac{n P_{M}+(n-1) P_{M-1}+\ldots+2 P_{(M-n+2)}+P_{(M-n+1)}}{n+(n-1)+\ldots+2+1}
$$

2. Dengan menggunakan nilai dasar yang diperoleh, hitung nilai hasil peramalan dengan menggunakan persamaan berikut,

$$
W E M A_{\mathrm{t}}=\alpha \cdot Y_{\mathrm{t}}+(1-\alpha) \cdot H_{\mathrm{t}}
$$

dimana $Y_{t}$ adalah nilai pada periode waktu ke-t, $H_{t}$ adalah nilai dasar untuk suatu periode waktu $t$, dan $\alpha$ merupakan nilai derajat bobot yang menurun, yang diperoleh melalui persamaan berikut,

$$
\alpha=2 /(n+1)
$$

3. Kembali ke langkah (1) hingga seluruh data dalam data runtun waktu yang diberikan berakhir.

\section{B. MSE (Mean Square Error)}

Kriteria MSE menyatakan besarnya kesalahan rata-rata kuadrat dari suatu metode peramalan [9], dengan rumus perhitungan

$$
M S E=\frac{\sum_{t=1}^{n} e_{t}^{2}}{n},
$$

dimana $n$ menyatakan jumlah data dan $e_{t}$ adalah nilai kesalahan hasil ramalan yang diperoleh dari $X_{t}-\hat{X}_{t}$. Dalam hal ini, $X_{t}$ adalah nilai data aktual dan $\widehat{X}_{t}$ adalah nilai ramalannya.

\section{MAPE (Mean Absolute Percentage Error)}

Nilai MAPE memberikan petunjuk mengenai seberapa besar rata-rata kesalahan absolut peramalan dibandingkan dengan nilai sebenarnya [9], dan dinyatakan dengan rumus

$$
\text { MAPE }=\frac{\sum_{t=1}^{n}\left|\frac{\varepsilon_{t}}{x_{t}}\right|}{n} \times 100,
$$

dimana $n$ adalah jumlah data dan $e_{t}$ adalah nilai kesalahan ramalan yang diperoleh dari $X_{t}-\ddot{X}_{t}$. Nilai data aktual dinotasikan dengan $X_{t}$ dan $\dot{X}_{t}$ adalah nilai ramalannya.

\section{Arsitektur Sistem}

Untuk menerapkan pendekatan WEMA pada data IHSG (Indeks Harga Saham Gabungan), peneliti mengembangkan sebuah sistem berbasis web, dengan menggunakan scripting language PHP (PHP Hypertext Preprocessor). Sistem yang dibangun hanya digunakan untuk kepentingan penelitian, sehingga belum dipublikasikan saat ini. Adapun lingkungan perangkat keras maupun perangkat lunak yang digunakan dalam pengembangan dan pembangunan sistem adalah sebagai berikut,

1. Windows 7 Professional 64-bit,

2. Prosesor Intel ${ }^{\circledR}$ Core $^{\mathrm{TM}} \mathrm{i} 5$,

3. Memori 2048MB RAM,

4. Hard disk dengan kapasitas $280 \mathrm{~GB}$,

5. Layar monitor 12.1",

6. Keyboard dan mouse,

7. PHP version 5.3.1,

8. PHP Excel Reader library,

9. JPGraph 3.5.0 library.

Sistem yang dibangun dapat menerima data masukan (input data) dari suatu data runtun waktu yang sebelumnya telah disimpan dalam format Microsoft Excel ('.xls'). Selanjutnya sistem akan menjalankan proses komputasi sesuai dengan langkah-langkah metode WEMA yang telah dijelaskan sebelumnya untuk periode data yang diberikan. Hasil peramalan data kemudian ditampilkan dan dianalisis terhadap data aktual untuk mengetahui tingkat akurasi dan tingkat kehandalan hasil peramalan menggunakan kriteria MSE dan MAPE.

\section{HASIL DAN PEMBAHASAN}

Melalui langkah-langkah peramalan yang telah dijelaskan pada subbab sebelumnya, peneliti mencoba untuk menerapkan metode WEMA pada data IHSG. Jumlah data yang digunakan adalah 49 data yang direkam sejak 2 September 2013 hingga 12 November 2013 secara harian [10]. Panjang data span (yakni jumlah titik data sebelumnya yang diambil dari data terakhir) yang digunakan adalah 5. Kriteria MSE (Mean Square Error) dan MAPE (Mean Absolute Percentage Error) akan digunakan untuk mengukur tingkat akurasi dan kehandalan dari data hasil peramalan yang dihasilkan terhadap data sebenarnya.

Gambar 1 memperlihatkan antarmuka utama sistem yang dibangun. Pengguna dapat menentukan sembarang nilai untuk data awal yang ingin digunakan 
dalam memulai peramalan, dan data span sebagaimana yang dijelaskan sebelumnya. Seperti yang terlihat pada Gambar 1, data awal yang digunakan dalam percobaan ini adalah 6 dan data span yang digunakan adalah 5, yang berarti bahwa perhitungan akan dimulai dari data ke-6 dalam data runtun waktu yang diberikan dengan menggunakan 5 data sebelumnya.

Analisis Data Runtun Waktu

New Weighted Exponential Moving Average

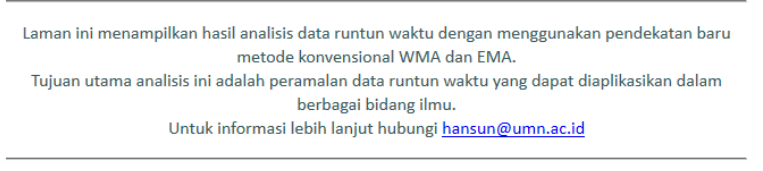

Data awal : 6

Span : 5

Proses Reset
Grafik data hasil peramalan dengan menggunakan metode WEMA diperlihatkan pada Gambar 2. Pada grafik tersebut, data sebenarnya direpresentasikan dengan garis warna biru, sementara data hasil peramalan direpresentasikan dengan garis warna merah disertai segitiga kecil yang menunjukkan posisi nilai data hasil peramalan tersebut. Selain itu, pada Gambar 2 juga terlihat nilai MSE dan MAPE untuk data awal dan data span yang digunakan, yakni 1860,5832 untuk MSE dan 0,7465 untuk MAPE.

Hasil perhitungan untuk masing-masing data dapat dilihat lebih jelas pada Tabel 1 yang disertakan.

Gambar 1. Antarmuka utama sistem

MAPE: 0.74653292908068

MSE : 1860.5832023244

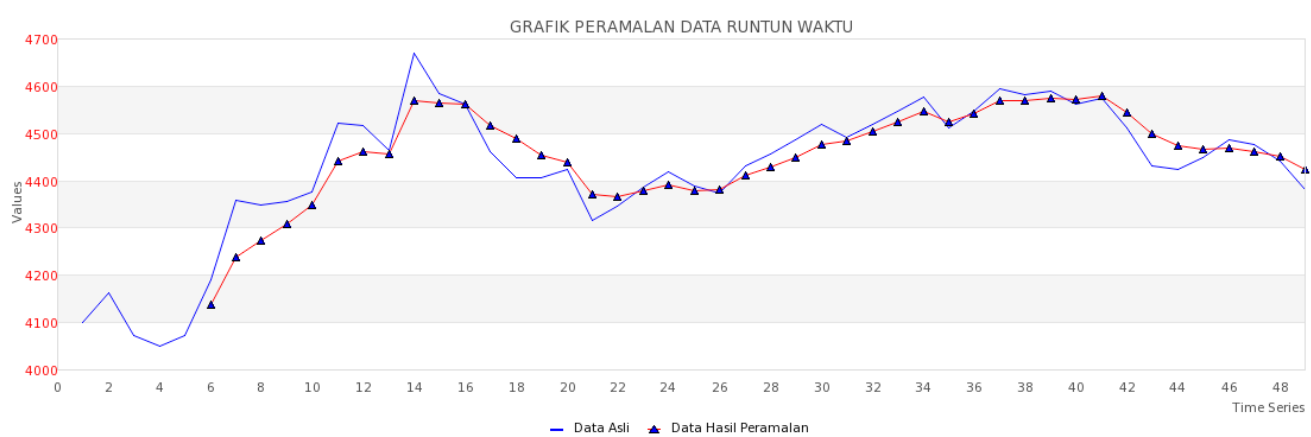

Gambar 2. Grafik data IHSG hasil peramalan dan data sebenarnya dengan menggunakan metode WEMA

\section{SIMPULAN}

Dari hasil ujicoba yang telah dilakukan, dapat disimpulkan bahwa pendekatan baru metode moving average, yakni Weighted Exponential Moving Average (WEMA) berhasil diterapkan untuk meramalkan data IHSG.

Hasil ujicoba pada 49 data indeks komposit IHSG memperlihatkan hasil peramalan yang cukup baik, terlihat dari nilai MSE dan MAPE yang cukup kecil, serta grafik data hasil peramalan yang cukup mendekati data sebenarnya mengikuti tren yang ada. Dengan demikian, para pelaku pasar dapat memanfaatkan hasil peramalan data IHSG dengan pendekatan WEMA, untuk memperkirakan pergerakan harga saham di masa mendatang.

\section{DAFTAR PUSTAKA}

[1] OECD: Glossary of Statistical Terms, http://stats.oecd.org/ glossary/detail.asp?ID=2708, diakses 3 November 2013 .
[2] Subanar dan Suhartono, 2009, Wavelet Neural Networks untuk Peramalan Data Time Series Finansial, Program Penelitian Ilmu Dasar Perguruan Tinggi, FMIPA UGM, Yogyakarta.

[3] Boediono dan Koster, W., 2001, Teori dan Aplikasi Statistika dan Probabilitas, PT. Remaja Rosdakarya, Bandung.

[4] Render, B., Stair Jr., R.M. dan Hanna, M.E., 2003, Quantitative Analysis for Management, 8th edition, Pearson Education, Inc., New Jersey.

[5] C. Murphy, "Moving averages tutorial," http://courses.jmsc. hku.hk/ jmsc7008spring2012/files/2010/02/MovingAverages. pdf, diakses 13 Oktober 2013.

[6] N. E. Hwa, "Different uses of moving average (MA)," http:// www.chartnexus.com/learning/static/pulses_apr2007.pdf, diakses 13 Oktober 2013.

[7] Hansun, S., 2013, A New Approach of Moving Average Method in Time Series Analysis, 2013 Conference on New Media Studies (CoNMedia), Proceeding, http://ieeexplore.ieee.org/xpl/articleDetails. jsp?tp=\&arnumber $=6708545 \&$ queryText\%3Dseng + hansun

[8] S. Dash, "A comparative study of moving averages: simple, weighted, and exponential," http://www.tradestation.com/ education/labs/analysis-concepts/a-comparative-study-ofmoving-averages, diakses 13 Oktober 2013. 
[9] Hansun, S., 2013, Jakarta Stock Exchange (JKSE) Forecasting using Fuzzy Time Series, Robotics, Biomimetics, and Intelligent Computational Systems (ROBIONETICS), Proceeding, http://ieeexplore.ieee.org/xpl/articleDetails. jsp?tp $=$ \&arnumber $=6743592 \&$ queryText $\% 3$ Dseng + hansun
[10] Yahoo! Finance, http://finance.yahoo.com/q/ $\mathrm{hp} ? \mathrm{~s}={ }^{\wedge} \mathrm{JKSE} \& \mathrm{a}=08 \& \mathrm{~b}=1 \& \mathrm{c}=2013 \& \mathrm{~d}=10 \& \mathrm{e}=12$ $\& \mathrm{f}=2013 \& \mathrm{~g}=\mathrm{d}$, diakses 12 November 2013.

Tabel 1 Hasil Peramalan Data IHSG

\begin{tabular}{|c|c|c|c|c|}
\hline Date & Data & Forecast & $\left(X_{t}-\hat{X}_{t}\right)^{2}$ & $\frac{\left|X_{t}-\hat{X}_{t}\right|}{X_{t}}$ \\
\hline $9 / 2 / 2013$ & 4101.23 & & & \\
\hline $9 / 3 / 2013$ & 4164.01 & & & \\
\hline $9 / 4 / 2013$ & 4073.46 & & & \\
\hline $9 / 5 / 2013$ & 4050.86 & & & \\
\hline $9 / 6 / 2013$ & 4072.35 & & & \\
\hline $9 / 9 / 2013$ & 4191.26 & 4139.125 & 2718.0582 & 0.0124 \\
\hline $9 / 10 / 2013$ & 4358.14 & 4237.783 & 14485.8235 & 0.0276 \\
\hline $9 / 11 / 2013$ & 4349.42 & 4272.364 & 5937.5929 & 0.0177 \\
\hline $9 / 12 / 2013$ & 4356.6 & 4309.743 & 2195.5026 & 0.0108 \\
\hline $9 / 13 / 2013$ & 4375.54 & 4348.758 & 717.2577 & 0.0061 \\
\hline $9 / 16 / 2013$ & 4522.24 & 4440.921 & 6612.7496 & 0.0180 \\
\hline $9 / 17 / 2013$ & 4517.62 & 4462.090 & 3083.5957 & 0.0123 \\
\hline $9 / 18 / 2013$ & 4463.25 & 4456.758 & 42.1508 & 0.0015 \\
\hline $9 / 19 / 2013$ & 4670.73 & 4569.398 & 10268.1067 & 0.0217 \\
\hline $9 / 20 / 2013$ & 4583.83 & 4565.133 & 349.5749 & 0.0041 \\
\hline $9 / 23 / 2013$ & 4562.86 & 4562.735 & 0.0155 & $2.73 \mathrm{E}-5$ \\
\hline $9 / 24 / 2013$ & 4460.41 & 4517.938 & 3309.4708 & 0.0129 \\
\hline $9 / 25 / 2013$ & 4406.77 & 4488.109 & 6616.0058 & 0.0185 \\
\hline $9 / 26 / 2013$ & 4405.89 & 4453.916 & 2306.4854 & 0.0109 \\
\hline $9 / 27 / 2013$ & 4423.72 & 4440.062 & 267.0440 & 0.0037 \\
\hline $9 / 30 / 2013$ & 4316.18 & 4371.884 & 3102.9356 & 0.0129 \\
\hline $10 / 1 / 2013$ & 4345.9 & 4367.018 & 445.9840 & 0.0049 \\
\hline $10 / 2 / 2013$ & 4387.6 & 4379.046 & 73.1769 & 0.0020 \\
\hline $10 / 3 / 2013$ & 4418.64 & 4392.190 & 699.6057 & 0.0060 \\
\hline $10 / 4 / 2013$ & 4389.35 & 4378.743 & 112.5149 & 0.0024 \\
\hline $10 / 7 / 2013$ & 4374.96 & 4380.846 & 34.6443 & 0.0013 \\
\hline $10 / 8 / 2013$ & 4432.51 & 4411.491 & 441.8090 & 0.0047 \\
\hline $10 / 9 / 2013$ & 4457.44 & 4429.486 & 781.4290 & 0.0063 \\
\hline $10 / 10 / 2013$ & 4486.68 & 4449.054 & 1415.7215 & 0.0084 \\
\hline $10 / 11 / 2013$ & 4519.91 & 4477.808 & 1772.5423 & 0.0093 \\
\hline $10 / 16 / 2013$ & 4492.26 & 4483.430 & 77.9693 & 0.0020 \\
\hline $10 / 17 / 2013$ & 4518.93 & 4503.577 & 235.7030 & 0.0034 \\
\hline $10 / 18 / 2013$ & 4546.57 & 4524.614 & 482.0527 & 0.0048 \\
\hline $10 / 21 / 2013$ & 4578.18 & 4547.552 & 938.0820 & 0.0067 \\
\hline $10 / 22 / 2013$ & 4512.74 & 4524.476 & 137.7233 & 0.0026 \\
\hline $10 / 23 / 2013$ & 4546.5 & 4542.640 & 14.9029 & 0.0009 \\
\hline $10 / 24 / 2013$ & 4594.85 & 4569.042 & 666.0273 & 0.0056 \\
\hline $10 / 25 / 2013$ & 4580.85 & 4569.023 & 139.8727 & 0.0026 \\
\hline $10 / 28 / 2013$ & 4590.54 & 4574.262 & 264.9786 & 0.0036 \\
\hline $10 / 29 / 2013$ & 4562.77 & 4571.090 & 69.2288 & 0.0018 \\
\hline $10 / 30 / 2013$ & 4574.88 & 4578.614 & 13.9401 & 0.0008 \\
\hline $10 / 31 / 2013$ & 4510.63 & 4545.646 & 1226.0969 & 0.0078 \\
\hline $11 / 1 / 2013$ & 4432.59 & 4499.188 & 4435.2655 & 0.0150 \\
\hline $11 / 4 / 2013$ & 4423.29 & 4473.647 & 2535.8642 & 0.0114 \\
\hline $11 / 6 / 2013$ & 4449.76 & 4467.693 & 321.6011 & 0.0040 \\
\hline $11 / 7 / 2013$ & 4486.11 & 4468.924 & 295.3555 & 0.0038 \\
\hline $11 / 8 / 2013$ & 4476.72 & 4461.817 & 222.1000 & 0.0033 \\
\hline $11 / 11 / 2013$ & 4441.72 & 4451.105 & 88.0780 & 0.0021 \\
\hline $11 / 12 / 2013$ & 4380.64 & 4424.355 & 1911.0217 & 0.0100 \\
\hline
\end{tabular}

